\title{
Solution of Combined Economic Emission Dispatch with Demand Side Management Using Meta- heuristic Algorithms
}

\author{
Govind Rai Goyal*, Shelly Vadhera \\ Department of Electrical Engineering, National Institute of Technology, Kurukshetra, India
}

Corresponding Author Email: er.grgoyal@gmail.com

https://doi.org/10.18280/jesa.520205

Received: 13 January 2019

Accepted: 3 April 2019

\section{Keywords:}

demand side management, economic emission dispatch, load reduction, metaheuristic algorithm

\begin{abstract}
This paper deals with application of meta-heuristic algorithms to resolve the problem of combined economic emission dispatch (CEED) with peak load management for a mediumsized power system in an efficient manner. The objective is to optimize the fuel cost of generation simultaneously minimizing the environmental pollution caused by fossil fuel based power generating units working at their peak limits. In this paper combined problem of minimizing fuel cost and emission of flue gases $\left(\mathrm{NO}_{x}, \mathrm{CO}_{2}, \mathrm{SO}_{2}\right)$, is solved using Cuckoo search (CS) and Grasshopper optimization algorithm (GOA) via composite function of all four objectives with help of weight ratios and price penalty factors. Demand Side Management (DSM) measure is also applied at least expensive areas to manage the peak load condition at generating units. The problem is implemented on IEEE 30-bus system with 6 generator units. The simulation results of the CS algorithm for CEED with and without DSM have been compared with the results of GOA algorithm. The compound results obtained by CS algorithm for the problem of CEED with DSM validated its potential.
\end{abstract}

\section{INTRODUCTION}

Globally environment change is ascribed to excessive discharge of greenhouse gases, mainly carbon dioxide $\left(\mathrm{CO}_{2}\right)$. As per the British Petroleum's report on statistical review on world energy, released in June-2019, on an accounting globally $\mathrm{CO}_{2}$ emission in the year 2018 was 33508.4 million tons [1] and it is also reported that global coal consumption in 2017-18 was highest. The industrial revolution resulted in high concentration of $\mathrm{CO}_{2}$ in the Earth's atmosphere, approximately $35 \% . \mathrm{CO}_{2}$ discharge will still increase by $1.9 \%$ annually, if no preventive action is taken [2]. There is strong requirement of a clean environment which is the biggest challenge to all emission concentrated sectors. Here, problem of combined economic emission dispatch (CEED) is concerned because of in the optimum economic dispatch only operating cost is reduced and doesn't consider the environmental harness by flue gases [3]. This objective can be achieved through optimal allocation of real power among generators while satisfying the system constraints.

There are various optimization algorithms (conventional /evolutionary) available to find the solution of any linear or non-linear function. Some of conventional algorithms viz. Linear programming (LPP), Interior point (IP), Gradient method (GM), have been proposed to solve the different problems of power system successfully [4-8], but there are some problems associated with these algorithms found in literature are, local optimum solution, limited in solving unimodel and smooth objectives only [9-10]. The objective function of CEED is non-differential as well as nonlinear one [11]. So that, the solution of CEED problem may become confined at local optimum while solving with conventional methods [12]. Various nature inspired evolutionary algorithms like genetic algorithm (GA), firefly algorithm (FA), particle swarm optimization (PSO), cuckoo search (CS), and grasshopper optimization algorithm (GOA) were introduced by the time to overcome the problems associated with conventional algorithms. All these algorithms have demonstrated their efficacy in solving different objectives of various optimal power flow problems [13-16].

Demand side management (DSM) is integral part of smart grid. It can be benefited in various ways for all the sectors of power system and society like reduced cost of energy bills for residential consumers, and benefits for industrial consumers are lower production cost, reduced power cuts, on the other hand benefits for production houses are better utilization of resources, improved system reliability, reduced requirement of network expansion as well as installed capacity, cost-effective \& competitive business (reduced peak power prices) and as per environmental aspects DSM can result in reduced emission of greenhouse gases etc. Load control is one of the DSM techniques which is a systematic switching off of supply to any area by the utility in order to reduce the demand in peak hours [17-18]. Both the objectives of CEED problem i.e. minimization of fuel cost and minimization of gases emission are conflicting in nature. In order to minimize both the functions simultaneously, a function of total cost is taken into consideration [19]. In this paper, performance of GOA and CS algorithms is tested in finding optimal solution of problem of CEED with accounting the effect of DSM in peak load management. Here, optimal load control technique is used as DSM measures [20].

Rest of this paper is organized as follows, problem formulation with objectives functions and constraints followed by introduction of meta-heuristic algorithms. In section IV, simulation results are discussed, last but not the least section $\mathrm{V}$; presents major conclusion drawn from the work. 


\section{PROBLEM FORMULATION}

Objectives of combined economic emission dispatch (CEED) problem and their constraints are formulated mathematically by nonlinear functions as given in [21]:

\subsection{Objective functions of CEED problem}

\subsubsection{Power generation cost}

Sum of generation cost of 6 fossil fuel fired generators can be given by following equation:

$$
F(1)=\sum_{i=1}^{N G} a_{i} P g_{i}^{2}+b_{i} P g_{i}+c_{i}(\$ / h)
$$

Here, $a_{i}, b_{i}, c_{i}$ are coefficients of cost for generators and NG is the number of generating units.

\subsubsection{Emission of $\mathrm{SO}_{2}$ gas}

The sum of emission of $\mathrm{SO}_{2}$ gas of fossil fuel fired generators can be expressed in term of emission coefficients as:

$$
F(2)=\sum_{i=1}^{N G} l_{i} P g_{i}^{2}+m_{i} P g_{i}+n_{i}(k g / h)
$$

Here, $\mathrm{l}_{\mathrm{i}}, \mathrm{m}_{\mathrm{i}}, \mathrm{n}_{\mathrm{i}}$ are emission coefficients of $\mathrm{SO}_{2}$ gas.

\subsubsection{Emission of $\mathrm{CO}_{2}$ gas}

The sum of emission of $\mathrm{CO}_{2}$ gas of fossil fuel fired generators can also be given by following quadratic equation:

$$
F(3)=\sum_{i=1}^{N G} x_{i} P g_{i}^{2}+y_{i} P g_{i}+z_{i}(k g / h)
$$

Here, $\mathbf{x}_{\mathbf{i}}, \mathbf{y}_{\mathbf{i}}, \mathbf{z}_{\mathbf{i}}$ are emission coefficients of $\mathrm{CO}_{2}$ gas.

\subsubsection{Emission of NOx gas}

The sum of emission of NOx gas of fossil fuel fired generators can be expressed as follows:

$$
F(4)=\sum_{i=1}^{N G} d_{i} P g_{i}^{2}+e_{i} P g_{i}+f_{i}(k g / h)
$$

Here, $\mathrm{d}_{\mathrm{i}}, \mathrm{e}_{\mathrm{i}}, \mathrm{f}_{\mathrm{i}}$ are emission coefficients of NOx gas.

\subsection{Formulation of composite function}

The above mentioned objective functions of CEED problem can be converted into a composite function (CF) of cost with the help of price penalty factors $(\mathrm{H})$ as follows:

$$
C F=F(1)+F(2) * H_{1-2}^{\max }+F(3) * H_{1-3}^{\max }+F(4) * H_{1-4}^{\max }(\$ / h)
$$

Here, price penalty factors $\mathrm{H}_{1-2}{ }^{\max }, \mathrm{H}_{1-3}{ }^{\max }, \mathrm{H}_{1-4^{\max }}$ are the ratios of maximum generation cost and maximum emission of $\mathrm{SO}_{2}, \mathrm{CO}_{2}, \mathrm{NO}_{\mathrm{X}}$ respectively as given in equation (6). Price penalty factors combine the functions of $\mathrm{SO}_{2}, \mathrm{CO}_{2}, \mathrm{NO}_{\mathrm{X}}$ and cost [22].

$$
\begin{aligned}
& H_{l-2}^{\max }=\frac{\sum_{i=1}^{N G} c_{i}+b_{i} P_{i}^{m}+a_{i}\left(P_{i}^{m}\right)^{2}}{\sum_{i=1}^{N G} n_{i}+m_{i} P_{i}^{m}+l_{i}\left(P_{i}^{m}\right)^{2}}(\$ / K g) \\
& H_{1-3}^{\max }=\frac{\sum_{i=1}^{N G} c_{i}+b_{i} P_{i}^{m}+a_{i}\left(P_{i}^{m}\right)^{2}}{\sum_{i=1}^{N G} z_{i}+y_{i} P_{i}^{m}+x_{i}\left(P_{i}^{m}\right)^{2}} \overbrace{(\$ / K g)} \\
& H_{1-4}^{\max }=\frac{\sum_{i=1}^{N G} c_{i}+b_{i} P_{i}^{m}+a_{i}\left(P_{i}^{m}\right)^{2}}{\sum_{i=1}^{N G} f_{i}+e_{i} P_{i}^{m}+d_{i}\left(P_{i}^{m}\right)^{2}}(\$ / K g)
\end{aligned}
$$

To optimize all the functions simultaneously, four weighting factors $\mathrm{w}_{1}, \mathrm{w}_{2}, \mathrm{w}_{3}$, and $\mathrm{w}_{4}$ are also introduced which have their value in range of $[0,1]$. The composite function $(\mathrm{CF})$ which is the sum of fuel cost and implied emission cost can be expressed as follows:

$$
C F=w_{1} F(1)+w_{2} F(2) * H_{1-2}^{\max }+w_{3} F(3) * H_{1-3}^{\max }+w_{4} F(4) * H_{1-4}^{\max }(\$ / h)
$$

\subsection{Formulation of load reduction cost}

The implied cost of load reduction can be modelled as a negative load in the composite function of CEED. Sum of the cost of load reduction (CLR) for $\mathrm{N}_{\mathrm{d}}$ units is calculated as equation given in [20]:

$$
\begin{aligned}
& C \boldsymbol{L R}=\sum_{k=1}^{N d} h_{k} \boldsymbol{L}_{k}(\$ / h) \\
& h_{k}=b_{k}+2 a_{k} L_{k}(\$ / M W h)
\end{aligned}
$$

Here, $L_{k}$ is the power reduced from $k^{\text {th }}$ unit; $h_{k}$ is the coefficient of load reduction cost; and $\mathrm{N}_{\mathrm{d}}$ is the number of units those can be considered for power reduction.

\subsection{System constraints}

(1). In this paper the power balance equation is considered as equality constraint. In this $\mathrm{P}_{\mathrm{g}}$ is power generated, $\mathrm{P}_{\mathrm{d}}$ is demand power, and $\mathrm{P}_{1}$ represents line losses [23].

$$
\begin{gathered}
\sum_{i=1}^{N G} P g_{i}=\sum_{i=1}^{N B} P d_{i}+P l \\
P l=\sum_{k=1}^{N L} g_{k}\left[\left|V_{i}\right|^{2}+\left|V_{j}\right|^{2}-2\left|V_{i} \| V_{j}\right| \cos \left(d_{i}-d_{j}\right)\right](\mathrm{MW})
\end{gathered}
$$

It is the loss formula at $\mathrm{k}^{\text {th }}$ line connected between $\mathrm{i}^{\text {th }}$ and $\mathrm{j}^{\text {th }}$ bus.

(2). Limits of load reduced at $\mathrm{k}^{\text {th }}$ unit is also considered as inequality constraint [20]:

$$
L_{k}^{\min }<L_{k}<L_{k}^{\max }
$$




\section{META HEURISTIC ALGORITHMS}

\subsection{Cuckoo search (CS) algorithm}

\subsubsection{Overview}

This is a popular meta-heuristic algorithm, centred on brood parasitism of a family of birds named "Cuckoos". This algorithm finds the most suitable host nest on the basis of breeding behaviour of cuckoos [16].

\subsubsection{Steps of CS algorithm}

Following are the steps of cuckoo search algorithm [16,23]:

(1). Specify the objective function $\mathrm{f}(\mathrm{x})$

(2). Initialize the parameters as number of host nest, maxiteration

(3). Generate initial population of $\mathrm{n}$ host nest using equation given bellow

$$
x_{i}^{j}(0)=\operatorname{rand}\left(u p_{i}^{j}-\operatorname{low}_{i}^{j}\right)+\operatorname{low}_{i}^{j}
$$

$x_{i}^{j}=\mathrm{j}^{\text {th }}$ component of $\mathrm{i}^{\text {th }}$ nest; $u p_{i}^{j}=$ upper bounds of $\mathrm{j}^{\text {th }}$ component; lo $_{i}^{j}=$ lower bounds of $\mathrm{j}^{\text {th }}$ component

(4). Evaluate the objective function and store the best solution as vector

(5). Find out the step size, $\alpha$ using the current solution (X) and best solution (Gbest) by the following equation

$$
\alpha=0.01 *_{\mathrm{s}}(\mathrm{X}-\mathrm{Gbest})
$$

(6). At each iteration new solutions are generated by using following equation :

$$
\mathrm{X}^{\mathrm{t}+1}=\mathrm{X}^{\mathrm{t}}+\alpha \oplus \operatorname{Levy}(\lambda)
$$

(7). A fraction of worst nest are abandoned and replaced by new solutions by probability $(\mathrm{Pa})$.

(8). Compare the fitness value of current and previous iteration $\mathrm{F}(\mathrm{t})>\mathrm{F}(\mathrm{t}-1)$

(9). Check for max-iteration or go for iterations until a satisfied condition is met.

\subsection{Grasshopper optimization algorithm (GOA)}

\subsubsection{Overview}

GOA is also a meta-heuristic algorithm, based on swimming behaviour of grasshoppers and their social interaction. These insects basically damage the crops. Swimming behaviour of grasshoppers can be written as [24]:

$$
\mathrm{X}_{\mathrm{i}}=\mathrm{S}_{\mathrm{i}}+\mathrm{G}_{\mathrm{i}}+\mathrm{A}_{\mathrm{i}}
$$

$\mathrm{X}_{\mathrm{i}}=$ position of $\mathrm{i}^{\text {th }}$ grasshopper; $\mathrm{S}_{\mathrm{i}}=$ social interaction; $\mathrm{G}_{\mathrm{i}}=$ gravity force; $\mathrm{A}_{\mathrm{i}}=$ wind force.

\subsubsection{Initialization}

GOA is also initialized with some random solutions like other evolutionary algorithms using following equation [24].

$$
X_{i}=X_{i}^{\min }+\operatorname{rand}()^{*}\left(X_{i}^{\max }-X_{i}^{\min }\right)
$$

Here, NP shows the number of grasshoppers, $(i=1$, 2......NP)

The variable $\mathrm{c}$ is used to reduce the effect of attraction and repulsion forces between grasshoppers [25].

$$
c=c_{\text {Max }}-i t r\left(\frac{c_{\text {Max }}-c_{\text {Min }}}{i t r_{\max }}\right)
$$

where, cMax and cMin are respectively the maximum and minimum values of parameter c [24-25].

\section{SIMULATION STUDY \& RESULTS}

Problem of CEED with and without implementing DSM is tested on standard IEEE-30 bus system with 6 generating units. This system consists of 22 load-buses and 48 lines. Generators are connected at bus numbers $2,5,8,11,13$. Standard values of coefficients for fuel cost and emission dispatch of $\mathrm{CO}_{2}$ gas, $\mathrm{SO}_{2}$ gas and $\mathrm{NO}_{\mathrm{X}}$ gas are given in Table (4) and Table (5) respectively [22]. Values of price penalty factors given in Table (2) are calculated using equation numbers (6). Functions of gases emission $\mathrm{F}(2), \mathrm{F}(3)$ and $\mathrm{F}(4)$ are multiplied with respective price penalty factors to make possible their addition with fuel cost function $F(1)$. All the four objective functions are converted into a composite function $(\mathrm{CF})$ and optimized by $\mathrm{CS}$ and GOA techniques using MATLAB-2013. Parameters of $\mathrm{CS}$ and GOA algorithms are set by various trials and included in Table (1). Table (3) also gives the data used for load reduction while applying DSM like range of load that can be curtailed.

Table 1. Parameters set of CS and GOA algorithms

\begin{tabular}{clc}
\hline $\begin{array}{c}\text { S. } \\
\text { No. }\end{array}$ & \multicolumn{1}{c}{ Parameter } & Value \\
\hline 1 & Numbers of cuckoo's nests in CS (n) & 30 \\
2 & Rate of discovery in CS (pa) & $1 / 4^{\text {th }}$ \\
3 & Numbers of grasshoppers in GOA (N) & 20 \\
4 & Numbers of decision variables in (D) & 06 \\
5 & Penalty factor in CS \& GOA (k) & 10 \\
6 & Max iterations count & 500 \\
7 & cMax for GOA & 1 \\
8 & cMin for GOA & 0.00001 \\
\hline
\end{tabular}

Table 2. Values of price penalty factors

\begin{tabular}{cccccc}
\hline Gen. & $\mathbf{P}_{\mathbf{g}}{ }^{\mathbf{m i n}}$ & $\mathbf{P}_{\mathbf{g}}{ }^{\mathbf{m a x}}$ & \multicolumn{3}{c}{ Price Penalty Factors } \\
Unit & $(\mathbf{M W})$ & $(\mathbf{M W})$ & $\mathbf{H}_{\mathbf{1 - 2}}{ }^{\mathbf{m a x}}$ & $\mathbf{H}_{\mathbf{1 - 3}}{ }^{\mathbf{m a x}}$ & $\mathbf{H}_{\mathbf{1 - 4}}{ }^{\mathbf{m a x}}$ \\
\hline 1 & 50 & 100 & 2.762 & 0.017 & 1.108 \\
2 & 20 & 80 & 9.914 & 0.079 & 10.526 \\
3 & 15 & 50 & 27.659 & 0.632 & 2.615 \\
4 & 10 & 30 & 9.018 & 0.151 & 0.450 \\
5 & 10 & 25 & 27.849 & 0.631 & 2.614 \\
6 & 12 & 25 & 6.651 & 0.017 & 4.022 \\
\hline
\end{tabular}

Minimized fuel cost as well as emission dispatch for generation of 295.64 MW (load demand 284 MW and transmission losses $10 \mathrm{MW}$ ) is given in Table (6). Here load demand is calculated from standard load data of IEEE 30 bus system. It is noticed that in case of without DSM, unit 1 and 2 are working near to their peak limits. Comparative results shown in Figure 1 and Figure 2 demonstrate that peak load at units 1 and 2 can be reduced and also saving can be achieved by applying the DSM. Here, optimal load is curtailed by 
applying load control as DSM measure. Total load reduced is 30.31 MW $\left(\mathrm{L}_{1}=16.520573 \mathrm{MW}\right.$, and $\left.\mathrm{L}_{2}=13.78942 \mathrm{MW}\right)$ and an optimal cost of load reduction (CLR) is added in total cost. Fig. 3(a), 3(b), 3(c) and 3(d) shows the characteristic curves for minimization of fuel cost, $\mathrm{CO}_{2}, \mathrm{NO}_{\mathrm{x}}$ and $\mathrm{SO}_{2}$ respectively.

Table 3. Load reduction data

\begin{tabular}{cccc}
\hline $\begin{array}{c}\text { Gen. Unit } \\
(\mathbf{k})\end{array}$ & $\begin{array}{c}\text { Lkmin } \\
(\mathbf{M W})\end{array}$ & $\begin{array}{c}\text { Lkmax } \\
(\mathbf{M W})\end{array}$ & $\begin{array}{c}\text { Cost coefficient of } \\
\text { CLR, } \mathbf{h}_{\mathbf{k}}\end{array}$ \\
\hline 1 & 0 & 50 & $\mathrm{~h} 1=\mathrm{b} 1+2 \mathrm{a} 1 \mathrm{~L} 1$ \\
2 & 0 & 40 & $\mathrm{~h} 1=\mathrm{b} 2+2 \mathrm{a} 2 \mathrm{~L} 2$ \\
\hline
\end{tabular}

Table 4. Cost coefficients of IEEE 30 System

\begin{tabular}{|c|c|c|c|}
\hline \multirow[b]{2}{*}{ Gen. Unit } & \multicolumn{3}{|c|}{ Fuel cost coefficients } \\
\hline & $\underset{\left(\$ / \mathbf{M W h}^{2}\right)}{\mathbf{a}}$ & $\begin{array}{c}\mathbf{b} \\
(\$ / M W h)\end{array}$ & $\begin{array}{c}c \\
(\$ / h)\end{array}$ \\
\hline 1 & 0.0020 & 8.43 & 85.63 \\
\hline 2 & 0.0038 & 6.41 & 303.77 \\
\hline 3 & 0.0021 & 7.42 & 847.14 \\
\hline 4 & 0.0013 & 8.30 & 274.22 \\
\hline 5 & 0.0021 & 7.42 & 847.14 \\
\hline 6 & 0.0059 & 6.91 & 202.02 \\
\hline
\end{tabular}

Table 5. Coefficients of gases emission for IEEE 30 bus 6 generators system

\begin{tabular}{|c|c|c|c|c|c|c|c|c|c|}
\hline \multirow[b]{2}{*}{$\begin{array}{l}\text { Gen. } \\
\text { Unit }\end{array}$} & \multicolumn{3}{|c|}{$\mathrm{CO}_{2}$ Emission Coefficients } & \multicolumn{3}{|c|}{$\mathrm{SO}_{2}$ Emission Coefficients } & \multicolumn{3}{|c|}{ NOx Emission Coefficients } \\
\hline & $\begin{array}{c}\mathbf{x} \\
\left(\mathrm{Kg} / \mathbf{M W h}^{2}\right)\end{array}$ & $\begin{array}{c}\mathbf{y} \\
(\mathbf{K g} / \mathbf{M W h})\end{array}$ & $\begin{array}{c}\mathbf{z} \\
(\mathrm{Kg} / \mathrm{h}) \\
\end{array}$ & $\begin{array}{c}\text { l } \\
\left(\mathrm{Kg} / \mathbf{M W h}^{2}\right)\end{array}$ & $\underset{(\mathrm{Kg} / \mathrm{MWh})}{\mathbf{m}}$ & $\begin{array}{c}\mathbf{n} \\
(\mathrm{Kg} / \mathrm{h})\end{array}$ & $\begin{array}{c}\text { d } \\
\left(\mathrm{Kg} / \mathbf{M W h}^{2}\right)\end{array}$ & $\begin{array}{c}\mathrm{e} \\
(\mathrm{Kg} / \mathrm{MWh})\end{array}$ & $\begin{array}{c}\mathbf{f} \\
(\mathrm{Kg} / \mathrm{h})\end{array}$ \\
\hline 1 & 0.26 & -61.01 & 5080.14 & 0.0012 & 5.05 & 51.37 & 0.0063 & -0.38 & 80.90 \\
\hline 2 & 0.14 & -29.95 & 3824.77 & 0.0023 & 3.84 & 182.26 & 0.0064 & -0.79 & 28.82 \\
\hline 3 & 0.10 & -9.55 & 1342.85 & 0.0012 & 4.45 & 508.52 & 0.0031 & -1.36 & 324.17 \\
\hline 4 & 0.10 & -12.73 & 1819.62 & 0.0008 & 4.97 & 165.34 & 0.0067 & -2.39 & 610.25 \\
\hline 5 & 0.10 & -9.55 & 1342.85 & 0.0012 & 4.45 & 508.52 & 0.0031 & -1.36 & 324.17 \\
\hline 6 & 0.40 & -121.98 & 11381.07 & 0.0035 & 4.14 & 121.21 & 0.0061 & -0.39 & 50.38 \\
\hline
\end{tabular}

Table 6. Optimal setting of control variables for problem of CEED with equal weights $(0.25)$

\begin{tabular}{|c|c|c|c|c|c|c|}
\hline \multirow[t]{2}{*}{ S. No } & \multirow[t]{2}{*}{ Parameter } & \multirow{2}{*}{$\begin{array}{c}\text { Before } \\
\text { Optimization }\end{array}$} & \multicolumn{2}{|c|}{ Optimal Solution by CS algorithm } & \multicolumn{2}{|c|}{$\begin{array}{c}\text { Optimal Solution by GOA } \\
\text { algorithm }\end{array}$} \\
\hline & & & Without DSM & With DSM & Without DSM & With DSM \\
\hline 1 & Pg1 & 100.00 & 95.068 & 83.302 & 98.537 & 88.903 \\
\hline 2 & $\mathrm{Pg} 2$ & 80.00 & 79.794 & 71.059 & 78.498 & 71.513 \\
\hline 3 & Pg3 & 50.00 & 49.887 & 42.871 & 44.426 & 35.717 \\
\hline 4 & $\mathrm{Pg} 4$ & 25.00 & 25.871 & 26.071 & 26.907 & 26.202 \\
\hline 5 & Pg5 & 20.00 & 23.650 & 21.229 & 24.815 & 22.612 \\
\hline 6 & Pg6 & 20.00 & 21.372 & 20.798 & 22.437 & 20.533 \\
\hline 7 & Total Gen. (MW) & 295 & 295.64 & 265.33 & 295.62 & 265.48 \\
\hline 8 & Load Reduced (MW) & 0 & 0 & 30.31 & 0 & 30.14 \\
\hline 9 & Fuel Cost $(\$ / \mathrm{h})$ & 4859.78 & 4833.44 & 4585.81 & 4855.39 & 4598.89 \\
\hline 10 & $\mathrm{SO}_{2}$ Emission $(\mathrm{Kg} / \mathrm{h})$ & 2915.18 & 2892.10 & 2751.12 & 2902.59 & 2758.91 \\
\hline 11 & $\mathrm{CO}_{2}$ Emission $(\mathrm{Kg} / \mathrm{h})$ & 16881.52 & 14960.26 & 14858.61 & 15298.27 & 15265.81 \\
\hline 12 & NOx Emission $(\mathrm{kg} / \mathrm{h})$ & 377.78 & 370.41 & 320.37 & 373.67 & 326.54 \\
\hline 13 & $\begin{array}{l}\text { Load reduction cost } \\
\quad(\mathrm{CLR})(\$ / \mathrm{h})\end{array}$ & 0 & 0 & 416.65 & 0 & 451.59 \\
\hline 14 & Total Cost $(\$ / \mathrm{h})$ & 5915.14 & 5645.93 & 5325.48 & 5651.03 & 5332.45 \\
\hline
\end{tabular}

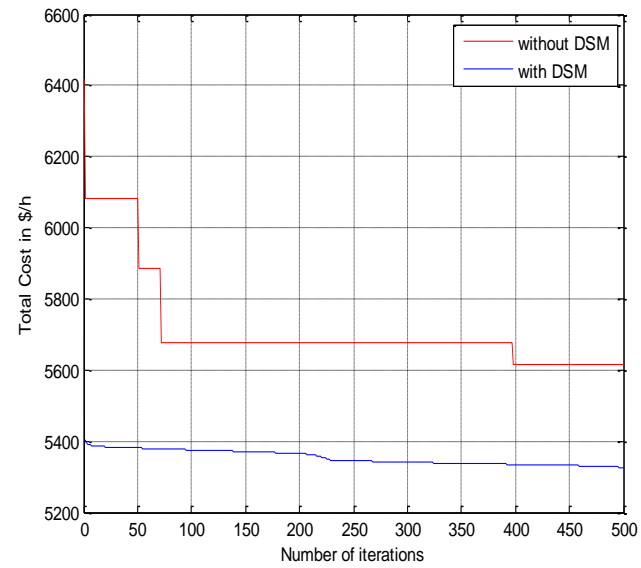

Figure 1. Comparative results for minimization of total cost by Cuckoo search algorithm

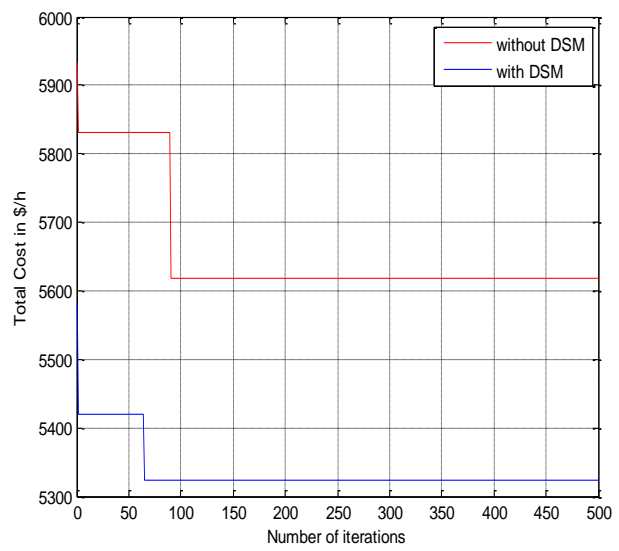

Figure 2. Comparative results for minimization of total cost by Grasshopper optimization algorithm 


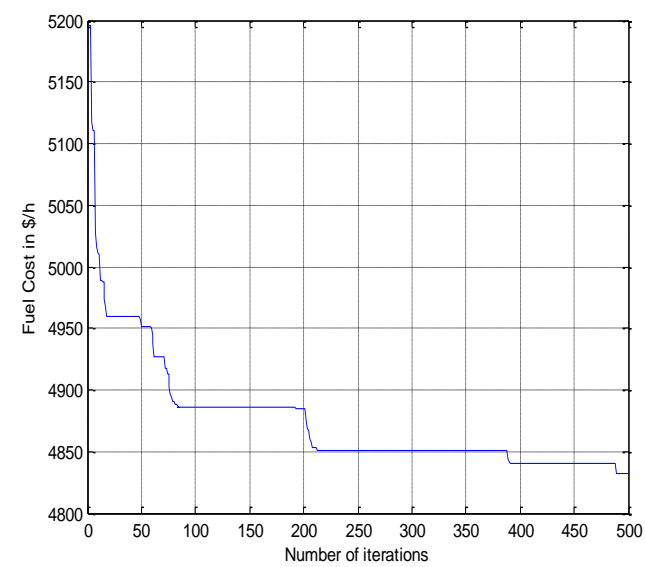

(a) Characteristic curve for fuel cost minimization

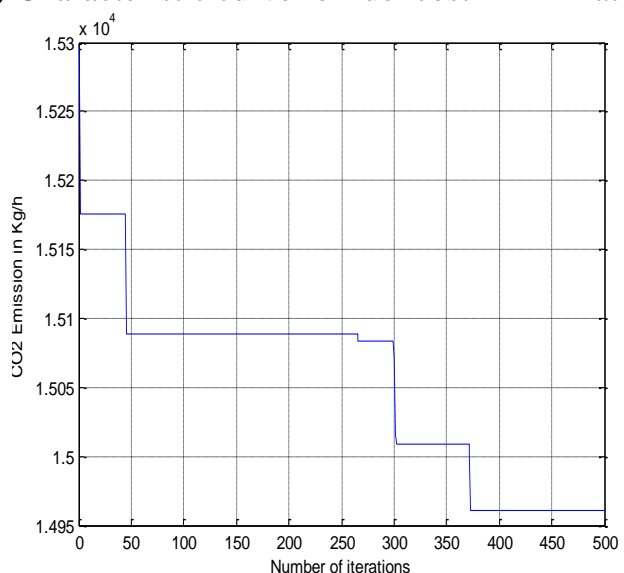

(b) Characteristic curve for minimization of $\mathrm{CO}_{2}$ emission

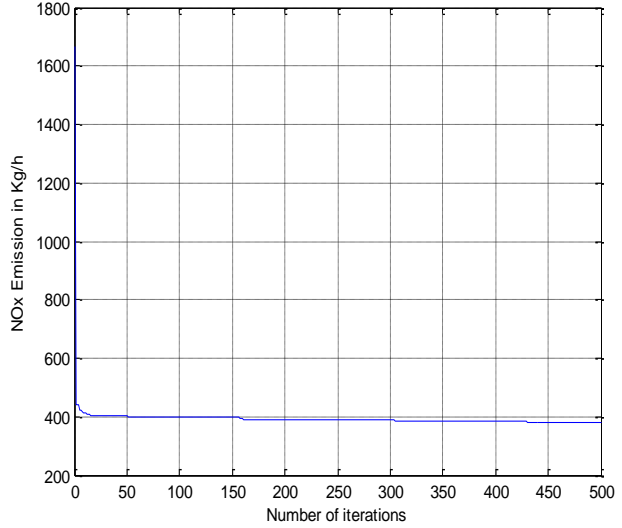

(c) Characteristic curve for minimization of NOx emission

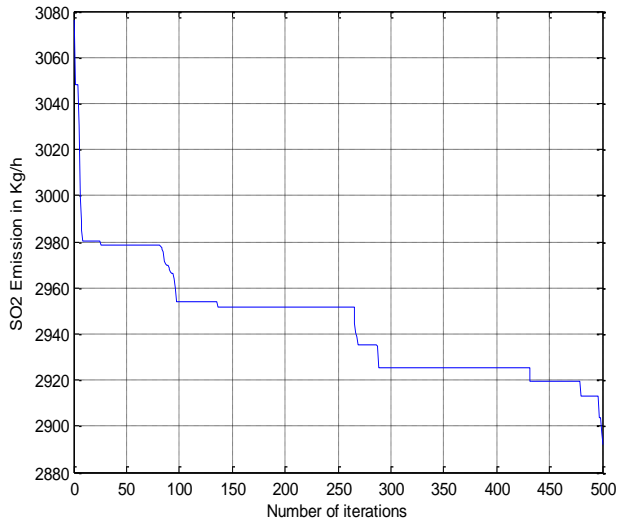

(d) Characteristic curve for minimization of $\mathrm{SO}_{2}$ emission

Figure 3. Characteristic curves for CEED without DSM by Cuckoo search algorithm

\section{CONCLUSION}

In this paper a comparative study to resolve the problem of combined economic emission dispatch (CEED) with and without applying DSM measures is given. Optimum fuel cost and emission dispatch of $\mathrm{SO}_{2}, \mathrm{CO}_{2}$ and $\mathrm{NOx}$ were calculated using Grasshopper optimization algorithm (GOA) and Cuckoo search (CS) algorithm in case of equal weights. Cuckoo search algorithm minimized all the four functions simultaneously in comparison of primary solution of load flow. Solutions obtained by CS algorithm are also more optimal than solutions of GOA. Some of the generating units are set at peak limits as given in the optimal solutions without DSM. This problem is resolved by applying optimal load reduction at least expensive units as a DSM measure. The optimal results obtained by simulation, and their comparative study demonstrate the ability and efficiency of DSM technique in handling peak load management. Application of DSM can also result in additional savings.

\section{REFERENCES}

[1] Global, B.P. (2019). Statistical review of world energy 2018. British Petroleum, London.

[2] Civicioglu, P., Besdok, E. (2013). A conceptual comparison of the Cuckoo-search, particle swarm optimization, differential evolution and artificial bee colony algorithms. Artificial Intelligence Review, 39(4): 315-346. https://doi.org/10.1007/s10462-011-9276-0

[3] El-Ela, A.A., Abido, M.A., Spea, S.R. (2011). Differential evolution algorithm for optimal reactive power dispatch. Electric Power Systems Research, 81(2): 458-464. https://doi.org/10.1016/j.epsr.2010.10.005

[4] Elanchezhian, E.B., Subramanian, S., Ganesan, S. (2014). Economic power dispatch with cubic cost models using teaching learning algorithm. IET Generation, Transmission \& Distribution, 8(7): 1187-1202. https://doi.org/10.1049/iet-gtd.2013.0603

[5] Granville, S. (1994). Optimal reactive dispatch through interior point methods. IEEE Transactions on Power Systems, 9(1): 136-146. https://doi.org/10.1109/59.317548

[6] Govindaraj, T., Udayakumar, S. (2014). Optimal reactive power planning and real power loss minimization using cuckoo search algorithm. International Journal of Innovative Research in Electrical, Electronics, Instrumentation and Control Engineering, 2(2): 1-5.

[7] Goyal, G.R., Mehta, H.D. (2015). Multi-objective optimal active power dispatch using swarm optimization techniques. In Proc. 5th Nirma University International Conference on Engineering (NUiCONE), pp. 1-6. https://doi.org/10.1109/NUICONE.2015.7449590

[8] Goyal, G.R., Mehta, H.D. (2015). Optimal dispatch of active and reactive power using cuckoo search method. IJIREEICE. https://doi.org/10.17148/IJIREEICE.2015.3204

[9] Gellings, C.W. (1985). The concept of demand-side management for electric utilities. In Proc. of the IEEE, 73(10):

$1468-1470$. https://doi.org/10.1109/PROC.1985.13318

[10] Han, C.G., Pardalos, P.M., Ye, Y. (1991). Solving some engineering problems using an interior-point algorithm. Pennsylvania State University, Department of Computer 
Science.

[11] Hashmi, A., Gupta, D., Goel, N., Goel, S. (2013). Comparative study of bio-inspired algorithms for unconstrained optimization problems. In International Conference on Advances in Electronics, Electrical \& Computer Engineering, 138-142. https://doi.org/10.3850/978-981-07-6935-2_28

[12] Hasan, Z., El-Hawary, M.E. (2016). Economic dispatch at peak load using load reduction for smart grid network. In Proc. IEEE Electrical Power and Energy Conference (EPEC), $\mathrm{pp}$

$1-5$. https://doi.org/10.1109/EPEC.2016.7771744

[13] Kim, K.S., Jung, L.H., Lee, S.C., Moon, U.C. (2006). Security constrained economic dispatch using interior point method. In Proc. International Conference on Power System Technology, pp. 1-6. https://doi.org/10.1109/ICPST.2006.321680

[14] Kumar, K.S., Tamilselvan, V., Murali, N., Rajaram, R., Sundaram, N.S., Jayabarathi, T. (2008). Economic load dispatch with emission constraints using various PSO algorithms. WSEAS Transactions on Power Systems, 3(9): 598-607.

[15] Khan, A.R., Mahmood, A., Safdar, A., Khan, Z.A., Khan, N.A. (2016). Load forecasting, dynamic pricing and DSM in smart grid: A review. Renewable and Sustainable Energy Reviews, 54: 1311-1322. https://doi.org/10.1016/j.rser.2015.10.117

[16] Lee, K.Y., Park, Y.M., Ortiz, J.L. (1985). A united approach to optimal real and reactive power dispatch. IEEE Transactions on Power Apparatus and Systems, (5): 1147-1153. https://doi.org/10.1109/TPAS.1985.323466

[17] Lokeshgupta, B., Sivasubramani, S. (2018). Multiobjective dynamic economic and emission dispatch with demand side management. International Journal of Electrical Power \& Energy Systems, 97: 334-343. https://doi.org/10.1016/j.ijepes.2017.11.020
[18] Mafarja, M., Aljarah, I., Heidari, A.A., Hammouri, A.I., Faris, H., Ala'M, A.Z., Mirjalili, S. (2018). Evolutionary population dynamics and grasshopper optimization approaches for feature selection problems. KnowledgeBased Systems, 145: 25-45. https://doi.org/10.1016/j.knosys.2017.12.037

[19] Sharma, A., Rai, G., Jain, M.P.K. (2017). Performance study of recent swarm optimization techniques with standard test functions. Imperial Journal of Interdisciplinary Research, 3(4): 6.

[20] Singh, L., Dhillon, J.S. (2007). Best weight pattern evaluation based security constrained power dispatch algorithm. Journal of Systems Science and Systems Engineering, 16(3): 287-307. https://doi.org/10.1007/s11518-007-5053-7

[21] Sen, G.D., Sharma, J., Goyal, G.R., Singh, A.K. (2017). A multi-objective PSO (MOPSO) algorithm for optimal active power dispatch with pollution control. Mathematical Modelling of Engineering Problems, 4(3): 113-19. https://doi.org/10.18280/mmep.040301

[22] Singh, H.P., Brar, Y.S., Kothari, D.P. (2014). Combined active and reactive power dispatch using particle swarm optimization. In Proc. Informing Science \& IT Education Conference (InSITE), pp. 295-304.

[23] Vargas, L.S., Quintana, V.H., Vannelli, A. (1993). A tutorial description of an interior point method and its applications to security-constrained economic dispatch. IEEE Transactions on Power Systems, 8(3): 1315-1324. https://doi.org/10.1109/59.260862

[24] Wei, W., Liang, Y., Liu, F., Mei, S., Tian, F. (2014). Taxing strategies for carbon emissions: A bilevel optimization approach. Energies, 7(4): 2228-2245.

[25] Yang, X.S., Suash, D. (2010). Engineering optimization by cuckoo search. arXiv preprint arXiv:1005.2908. 